\title{
O ecoturismo em Alagoas como um instrumento de adoção de boas práticas ambientais
}

\section{The ecotourism in Alagoas (Brazil) as an instrument for adoption to good environmental practices}

\author{
Rubens Pessoa de Barros, James Barros dos Santos
}

\begin{abstract}
RESUMO
O objetivo do trabalho foi realizar um levantamento de áreas naturais que têm o potencial ecoturístico em Alagoas para contribuir com boas práticas merecedoras de concepção e percepção ambiental através da interpretação ambiental e da Educação Ambiental como instrumentos de sensibilização e conservação. O Ecoturismo visto neste Estado é um segmento da atividade turística ambientalmente responsável que consiste em viajar para áreas naturais de forma sustentável. Desta forma, incentiva a conservação e busca a formação de uma consciência ambientalista através da interpretação do meio ambiente, promovendo a conservação do patrimônio natural, cultura e bem-estar da população local envolvida. Para a efetivação da pesquisa, foi feito um levantamento bibliográfico sobre a temática e de experiências vivenciadas no litoral, zona da mata e agreste e caatinga do Estado de Alagoas, onde possui um riquíssimo patrimônio natural e cultural encontrado do semiárido ao litoral. O trabalho teve início através de observação direta e registros fotográficos nas localidades visitadas em diferentes ecossistemas como a caatinga, a mata atlântica e a zona costeira durante o ano de 2008. Neste estudo, utilizou-se o método de pesquisa qualitativa, através de técnicas exploratórias tais como a pesquisa bibliográfica e a de campo. Os resultados mostraram locais com vocação para as seguintes atividades: as reservas de Mata Atlântica dos municípios de Murici e Maceió, ambos localizados na Zona da Mata, no semiárido; no município de Maravilha; e, no litoral sul, a Área de Proteção Ambiental Marituba do Peixe;
\end{abstract}

PALAVRAS-CHAVE: Ecoturismo; Educação Ambiental; Interpretação Ambiental. 


\begin{abstract}
The objective of this work was to develop a survey in natural areas which have potential for ecotourism in Alagoas in order to contribute to good practices which are worth of design and environmental awareness through environmental interpretation and environmental education as a tool to raise conservation awareness. Ecotourism in this state is seen as a responsible environmentally tourism which travels to natural areas in a sustainable manner. This way it encourages conservation and it searches for the formation of environmental awareness through interpretation of the environment, promoting heritage conservation of nature, culture and well-being of local people involved. For the implementation of the research there was a literature study on the subject and experiences in coastal, forest and rugged area and scrub of the State of Alagoas, which has a rich natural and cultural heritage found from the semiarid to the coast. The work started through direct observation and photographic records in the visited locations in different ecosystems such as savanna, a rainforest and coastal zone during the year 2008. In this present study, we used the method of qualitative research with exploratory techniques such as bibliographical and field research. The results showed areas suitable for this activity such as the Atlantic Forest reserves of municipalities of Murici and Maceió, both located in the Zona da Mata, in the semiarid, in Maravilha town; on the south coast; and, in the Environmental Protection Area of Marituba Fish.
\end{abstract}

KEYWORDS: Ecotourism, Environmental Education, Environmental Interpretation.

\title{
Introdução
}

O Ecoturismo é um segmento da atividade turística ambientalmente responsável, que consiste em viajar para áreas naturais de forma sustentável, incentiva a conservação e busca a formação de uma consciência ambientalista através da interpretação do meio ambiente, promovendo a conservação do patrimônio natural, cultura e bem-estar da população local envolvida. O Brasil é reconhecido internacionalmente pela grande diversidade biológica, possui uma enorme extensão territorial caracterizada por diferentes climas e geomorfologias em diversos ecossistemas que distinguem como país de maior potencialidade para 0 desenvolvimento do ecoturismo (DIAS, 2003).

Segundo a Organização Mundial do Turismo (OMT), enquanto o turismo cresce $7,5 \%$ ao ano, o ecoturismo cresce mais de $20 \%$. Estima-se que mais de meio milhão de pessoas no Brasil pratiquem o ecoturismo por ano, em geral, dentre as áreas protegidas, os Parques Nacionais, Estaduais e Municipais, as Florestas Nacionais e as Áreas de Proteção Ambiental (APAs), são as escolhidas para que se pratique o ecoturismo (NATURE UP MAGAZINE, 2009).

As motivações que levam pessoas a estarem buscando esse tipo de atividade refletem em suas necessidades intrínsecas e os estimulam a buscarem experiências que lhe tragam satisfação. Os turistas são motivados a apreciar o lazer na natureza por diversas razões, incluindo relaxamento, socialização, preocupação com o meio ambiente, maior conscientização ecológica, aventura, contato com diferentes culturas, enriquecimento intelectual, sendo assim, uma maneira de fugir da rotina e do estresse dos grandes centros urbanos. A vivência de atividades ligadas 
à natureza vem se tornando um importante aliado para melhoria da qualidade vida (SWARBROOKE, 2003).

Segundo Dias (2003), o ecoturismo, por si só, é considerado como uma estratégia de educação ambiental, uma vez que as viagens vivenciadas se tornem em experiências de aprendizado importante para contribuir na conservação da natureza. O Conselho Nacional do Meio Ambiente- CONAMA, (2002, s/p) definiu Educação Ambiental como "um processo de formação e informação, orientado para o desenvolvimento da consciência crítica sobre as questões ambientais e de atividade que levam à participação das comunidades na preservação do equilíbrio ambiental'. Pode-se afirmar que a educação ambiental, não deve centrar-se na divulgação dos conhecimentos ecológicos e ambientalistas, mas na construção e assimilação do todo.

A interpretação ambiental é uma ferramenta de trabalho utilizada na educação ambiental, no manejo de áreas protegidas e, mais recentemente, no ecoturismo. Para aplicar a atividade do ecoturismo em bases sustentáveis é necessário que respeite os princípios ambientais e sociais. $O$ papel da interpretação ambiental é fazer interagir o homem a natureza, a fim de informar-lhe, entretê-lo e sensibilizá-lo para as boas práticas ambientais (DIAS, 2004).

Egydio (1999) em sua concepção diz que a interpretação ambiental está na sensibilização e transmissão de informações aos visitantes, com o objetivo de traduzir a linguagem do meio ambiente nos aspectos naturais, culturais, históricos e sociais para linguagem comum dos visitantes, sendo assim uma forma mais acessível e adequada de interpretar a natureza, buscando estimular o visitante a pensar mais sobre as questões ambientais.

A interpretação ambiental no ecoturismo, além de ser educacional, possibilita formas diferenciadas de transmitir as informações. As trilhas ecológicas proporcionam aos visitantes uma compreensão e apreciação mais profunda dos recursos naturais e culturais das áreas visitadas. São usados como meios interpretativos: a interação entre público e o intérprete (guia de turismo), as placas e painéis, os folhetos, a própria trilha são formas de comunicação adequada para o entendimento do público. Existe uma infinidade de tópicos que merecem interpretação, tais como: biodiversidade, corredores ecológicos, geologia, hidrologia local, impactos ambientais (desmatamento, queimadas, poluição, extinção etc.) (DIAS, 2004).

O Potencial ecoturístico em Alagoas se predomina desde do semiárido ao litoral, é um Estado que apresenta variações topográficas e de umidade, e suas consequentes características ecológicas, possibilitam unir as paisagens diferenciadas em diferentes ecossistemas como a caatinga, a mata atlântica e a zona costeira (SALLES, 1995).

O objetivo da pesquisa foi fazer o levantamento de áreas naturais que tem o potencial do ecoturismo em Alagoas para contribuir com boas práticas merecedoras de percepção ambiental através da interpretação e da educação ambiental como instrumentos de sensibilização e conscientização. 


\section{Material e Métodos}

A pesquisa consistiu em um levantamento bibliográfico e de experiências vivenciadas em lugares visitados com o potencial do ecoturismo em Alagoas, durante o ano de 2008. Os atrativos naturais visitados da pesquisa foram na Zona da Mata no município de Murici que contem áreas contínuas de Mata Atlântica do Nordeste; outra região foi o Parque Municipal de Maceió que é uma reserva de 82 hectares de Mata Atlântica, situada na parte oeste da cidade; no semiárido a pesquisa foi realizada no município de Maravilha que possui um potencial para o turismo científico e natural, com as descobertas dos fósseis de animais pré-históricos; e na zona costeira, a pesquisa se concentrou no sul do litoral alagoano em uma Área de Proteção Ambiental chamada Marituba do Peixe com uma rica biodiversidade. A pesquisa foi qualitativa, na qual utilizou técnicas exploratórias tais como a pesquisa bibliográfica e a de campo com registros fotográficos.

Um trabalho semelhante foi realizado por (JESUS; RIBEIRO; FERRAZ, 2008) no Parque Nacional do Catimbau, criado em 2002, localizado no bioma caatinga, entre o agreste e o sertão pernambucano nos municípios de Buíque, Ibimirim e Tupanatinga. A pesquisa foi desenvolvida a partir do levantamento bibliográfico, documental e registros fotográficos, com o objetivo de contribuir para o enriquecimento da experiência do visitante e para sua sensibilização quanto à importância do bioma da caatinga, na qual este trabalho fez uma análise das potencialidades do Catimbau para a interpretação ambiental em trilhas e sugestões de como aproveitar adequadamente as oportunidades diagnosticadas.

\section{Localização da Pesquisa}

A Figura 1 revela as regiões ecoturísticas explorados da pesquisa, o Estado de Alagoas possui uma área geográfica de 27.767,66 Km², com 102 municípios, equivalente a $0,33 \%$ do território nacional e a $1,79 \%$ da região Nordeste do Brasil (IBGE, 2012). Na região leste, encontra-se a Zona da Mata e o Litoral; na região sul, o Baixo São Francisco; na região oeste, o Sertão e o Sertão do São Francisco e na região de transição, o Agreste. Tem temperatura quente 0 ano todo, mas a umidade varia, do litoral para o interior proporcionando dois tipos de clima: o quente e úmido, no Litoral e Zona da Mata; e quente e seco no Agreste e no Sertão (SALLES, 1994).

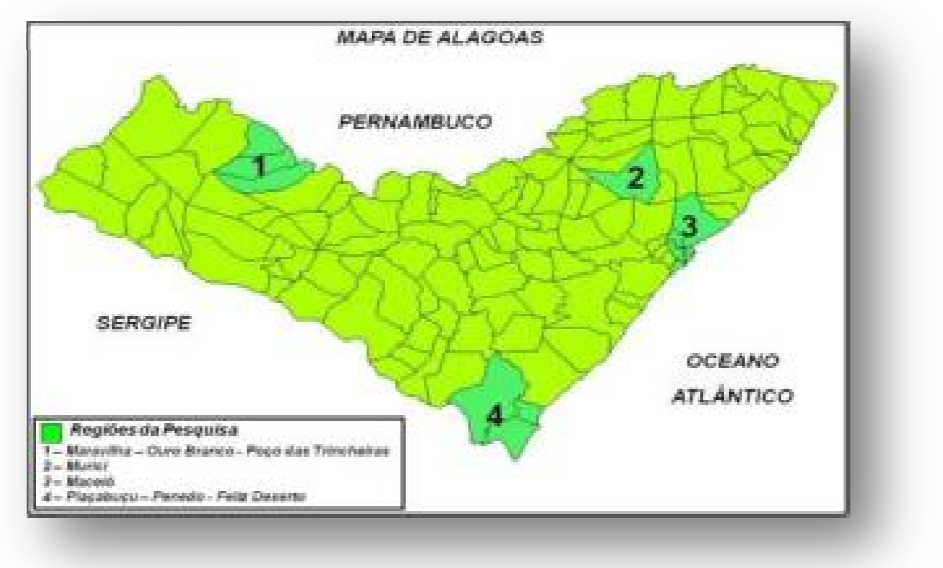

Figura 1: Mapa com as regiões ecoturísticas de Alagoas Software TerraView 3.2.0. Fonte: Adaptado pelo autor.

Figure 1: Map of ecotourism regions of Alagoas

Software terraView 3.2.0. Source: Adapted by the author. 


\section{Resultados e Discussões}

A prática do ecoturismo em Alagoas vem crescendo moderadamente, o principal produto turístico do Estado ainda é o turismo de sol e mar, o litoral alagoano possui aproximadamente $230 \mathrm{~km}$ de linha de costa e está localizado entre as coordenadas geográficas 848'12"S e 10²9'12" S (COMUNIDADES BENTÔNICAS, 2009), em um mar azul-esverdeado entre recifes, falésias e dunas, além disso, possui 17 lagoas, dentre essas, duas se destacam a Mundaú e Manguaba. Porém esse cenário turístico vem mudando nos últimos anos, a procura por lugares mais remotos e naturais e lugares remanescentes ainda preservados vem despertando a curiosidade dos visitantes que buscam novos desafios no Estado (SALLES, 1994).

As regiões visitadas sobre a pesquisa do ecoturismo em Alagoas para adoção de boas práticas ambientais revelaram um rico acervo natural ainda preservado para o uso sustentável da atividade turística. Um dos locais visitados foi à região serrana do município de Murici distante $48 \mathrm{~km}$ de Maceió, localizada em uma reserva ecológica na Zona da Mata alagoana que é uma das maiores áreas contínuas de Mata Atlântica do Nordeste, fica em relevo montanhoso entre encostas íngremes e vales, tem uma flora diversificada e várias nascentes. Nos locais mais preservados, as árvores atingem até $30 \mathrm{~m}$ de altura e retêm muita sombra e umidade, plantas herbáceas ornamentam o solo, caminhos e troncos, compondo ambiente de grande harmonia proporcionando a prática de trilhas ecológicas (CONSELHO NACIONAL DA RESERVA DA BIOSFERA DA MATA ATLÂNTICA, 2004).

$\mathrm{Na}$ região há uma trilha (Figura 2) que leva para a cachoeira da Tiririca que fica localizada em uma área de mata atlântica com caminhos íngremes e revela uma biodiversidade exuberante, o seu percurso pode durar duas horas de caminhada com uma aula de interpretação ambiental até a cachoeira que tem aproximadamente 70 metros de altura com queda d'água forte e gelada entre pedras enormes. Além da trilha para os que procuram maiores desafios pode-se praticar o Rapel na cachoeira (GUIA DE INFORMAÇÕES TURÍSTICAS, 2003).

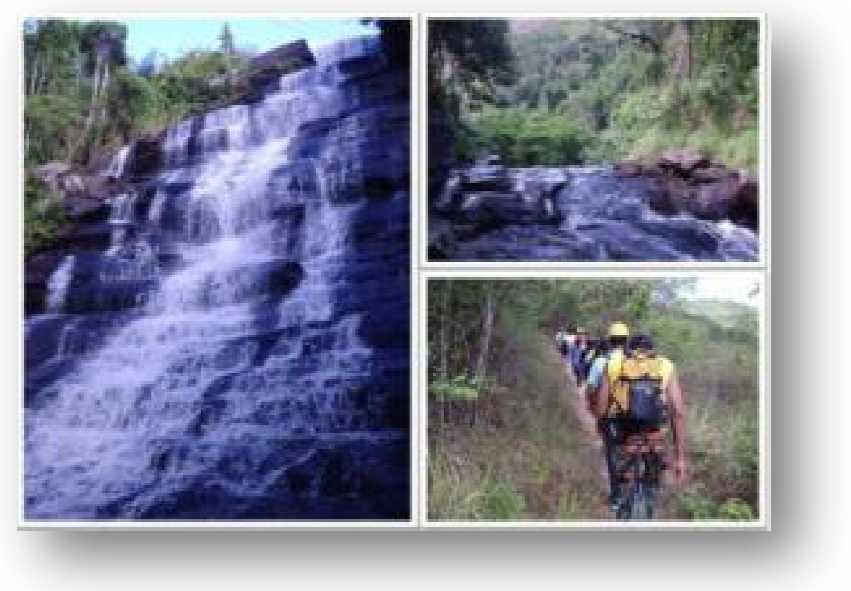

Figura 2: Cachoeira da Tiririca.

Fonte: Arquivo pessoal - adaptado pelo autor.

Figure 2: Waterfall Tiririca.

Source: Personal File - adapted by author 
No Parque Municipal de Maceió (Figura 3), criado pela Lei Municipal no 2514 de 27 de julho de 1978, se pratica o ecoturismo dentro da cidade. É uma área de 82, 4 hectares de preservação permanente que fica localizada entre os bairros de Bebedouro e Tabuleiro dos Martins. Dentro do Parque são oferecidos diversos serviços para os visitantes como trilhas ecológicas com o acompanhamento de monitores treinados, educação ambiental, com palestras e aulas práticas em espaço reservado para desenvolver atividades educativas e de lazer com a comunidade, além da distribuição de mudas de espécies da Mata Atlântica onde são produzidas em uma casa de vegetação. Na entrada principal do parque há um centro administrativo e um posto da Guarda Civil Municipal. No parque encontram-se diversas espécies de vegetação típica da Mata Atlântica como embaúba, ingazeiro, pau-brasil, além de uma fauna com a presença de mamíferos, aves e répteis (OUVERMUNDO, 2009).

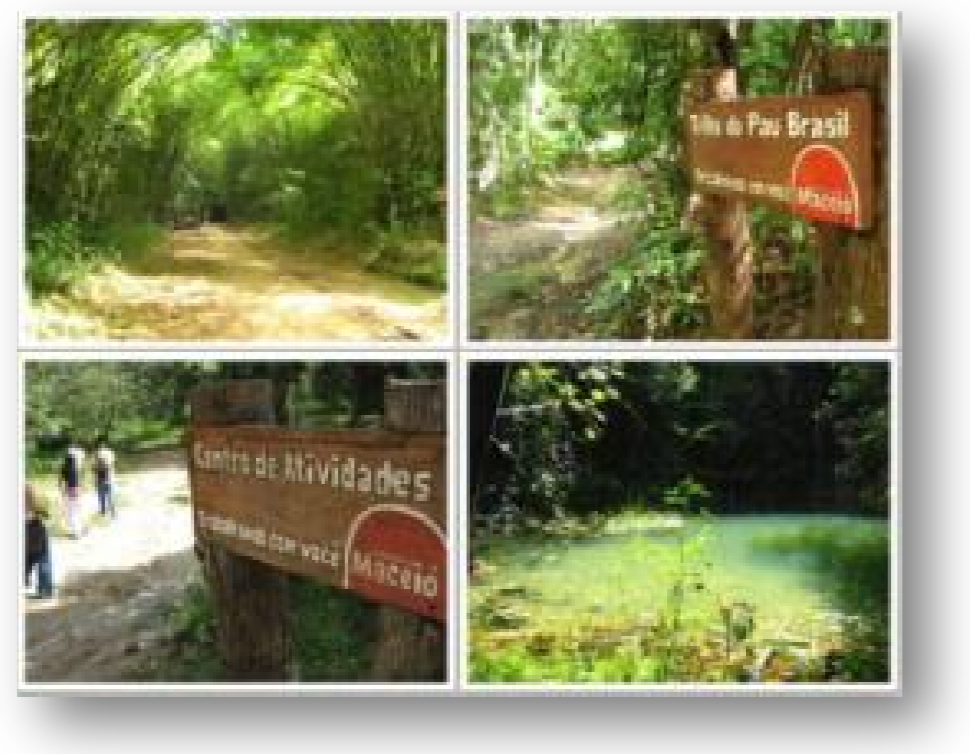

Figura 3: Parque Municipal de Maceió.

Fonte: Arquivo pessoal - adaptado pelo autor.

Figure 3: Maceió City Park.

Source: Personal File - adapted by author.

O Sertão oferece muitas opções de lazer em meio natural, o município de Maravilha que fica localizado a $240 \mathrm{~km}$ de Maceió no semiárido alagoano possui um potencial turístico científico e natural, com as descobertas dos fósseis de animais pré-históricos da megafauna do período pleistocênico, que datam de 39.000 anos. O responsável pela descoberta e embasamento científico é o paleontólogo do Museu de História Natural da Universidade Federal de Alagoas - UFAL, Jorge Luiz Lopes, que há mais de 10 anos estuda a região (ROCHA, 2007).

A cidade de Maravilha se transformou em um novo pólo turístico e diferenciado no Estado, juntos aos municípios vizinhos de Ouro Branco e Poço das Trincheiras, no qual os três municípios contam com sítios arqueológicos e geológicos, incluindo pinturas rupestres, além disso, Maravilha já se dispõe de um museu ex situ, inaugurado em 18 de maio de 2007 com peças em exposição retiradas das escavações e réplicas 
espalhadas na cidade (Figura 4) em tamanho real dos animais descobertos na região como preguiças gigantes com 6 metros de altura, tigre-dentes-desabre, toxodonte, mastodonte e o tatu gigante (LOPES, 2007).

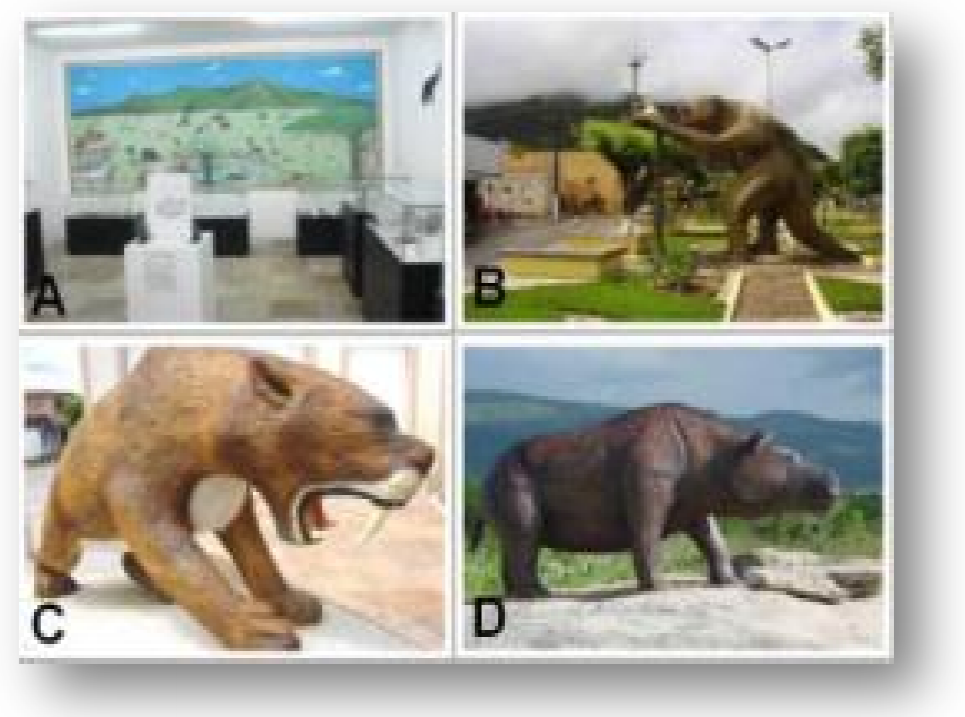

Figura 4: Museu ex situ - (A), réplicas de Preguiça Gigante - (B),

Tigre-dentes-de-sabre - (C) e Toxodonte - (D). Fonte: LOPES (2007) - Adaptado pelo autor.

Figure 4: Museum ex situ - (A), replicas of Giant Sloth - (B), Tiger-tooth saber - (C) and Toxodonte - (D). Source: LOPES (2007) - Adapted by the author.

Além dos fósseis encontrados, outro atrativo em Maravilha é a Serra da Caiçara (Figura 5) com 839 metros de altura, que proporciona uma paisagem cênica da região, para chegar ao cume da serra existe uma trilha de aproximadamente $2,5 \mathrm{~km}$ de extensão, durante o percurso da trilha é possível encontrar uma rica flora da caatinga e algumas espécies de orquídeas. Esta serra também é considerada brejo de altitude que diferencia das características da região em volta por apresentar áreas úmidas no meio da aridez, pode-se encontrar entre os maciços sertanejos a presença de árvores frutíferas, como mangueiras, e culturas de subsistências (SALLES, 2005).

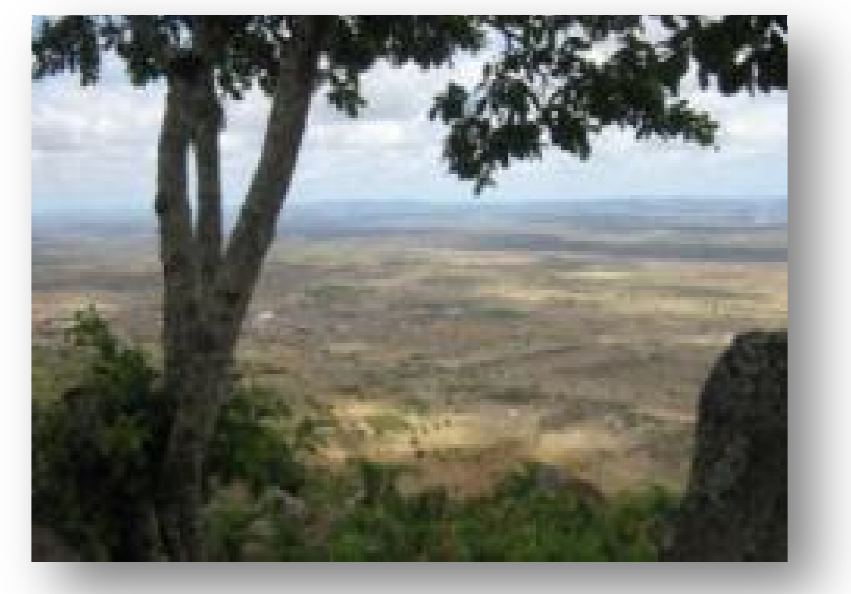

Figura 5: Vista da Serra da Caiçara. Fonte: Arquivo pessoal.

Figure 5: View of the Serra da Caiçara. Source: Personal archive 
A visita ao litoral sul de Alagoas foi direcionada a uma Área de Proteção Ambiental - APA, chamada Marituba do Peixe (Figura 6) criada pelo decreto estadual $N^{\circ} 35.858$ de 04 de março de 1988, conhecida também como Pantanal alagoano por apresentar uma feição geomorfológica de uma planície de inundação, semelhante com a do Pantanal Mato grossense, a região possui um potencial natural para a prática do ecoturismo. A APA tem uma área de influência de $185,56 \mathrm{~km}^{2} \mathrm{e}$ está localizada à margem esquerda do Rio São Francisco próximo a sua foz, Baixo São Francisco, em Alagoas, contida parcialmente nos territórios dos municípios de Penedo, Feliz Deserto e Piaçabuçu, é considerada a maior área alagada do Estado com uma importante relevância de diversidade biológica, no Plano de Manejo da APA foi catalogado 165 espécies de aves, um grande potencial para o turismo de observação de aves (Orniturismo) umas das modalidades da atividade do ecoturismo (PLANO DE MANEJO DA ÁREA DE PROTEÇÃO DO MARITUBA DO PEIXE, 2006).

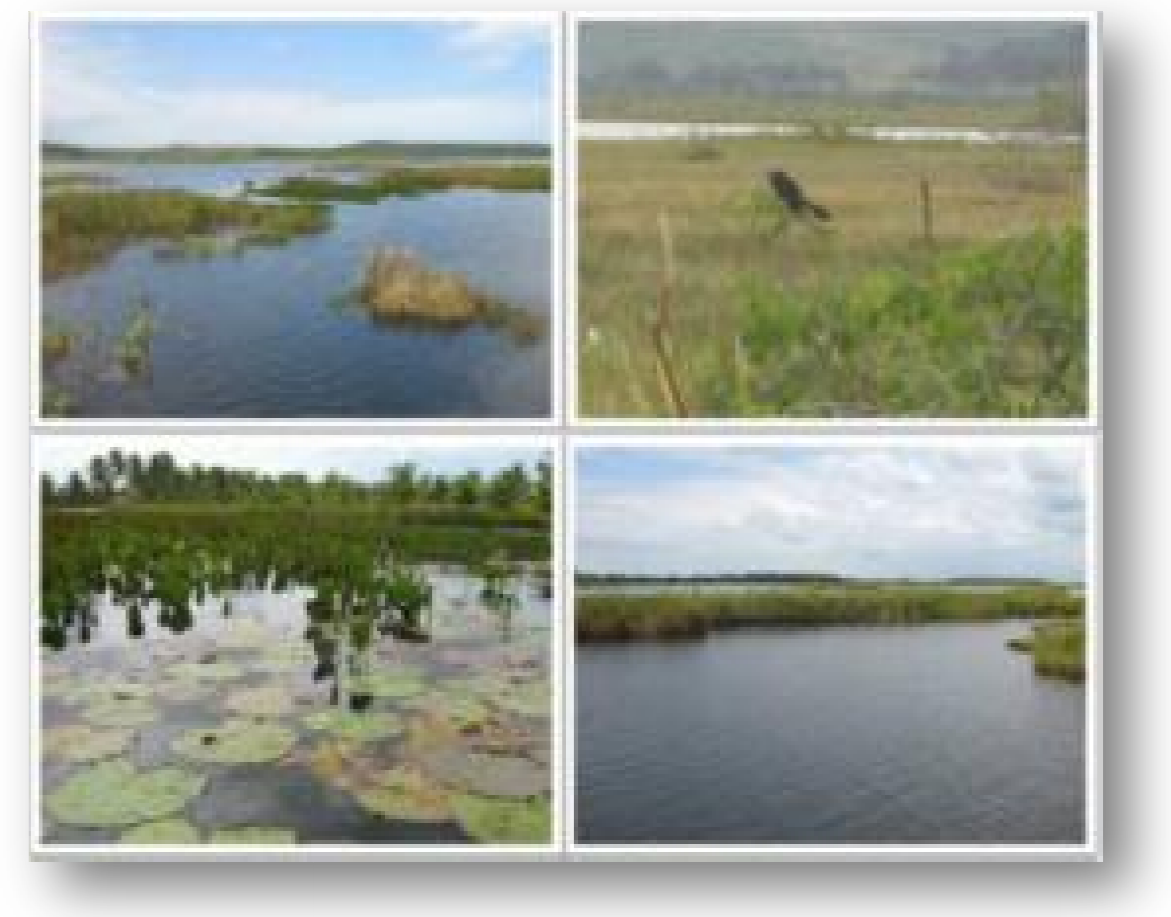

Figura 6: APA do Marituba do Peixe.

Fonte: Arquivo pessoal - adaptado pelo autor.

Figure 6: APA Marituba do Peixe.

Source: Personal File - adapted by the author.

A riqueza cultural existente na APA deve ser entendida também como um atrativo ecoturístico, respeitando hábitos e costumes locais, devendo ser incluído no planejamento turístico. Apesar da sua rica biodiversidade, o potencial turístico da APA é inexplorado, possibilitando assim a implantação de um turismo responsável (OMENA, 2006).

As áreas naturais, em particular as áreas protegidas legalmente, sua paisagem, fauna e flora - juntamente com os elementos culturais existentes - constituem grandes atrações, tanto para os habitantes dos 
países aos quais as áreas pertencem quanto para os turistas de todo o mundo. Por esse motivo, as organizações para a conservação reconhecem a enorme relevância do turismo e estão cientes dos inúmeros danos que um turismo mal administrado ou sem controle pode provocar no patrimônio natural e cultural do planeta (CEBALLOS-LASCURÁIN, 2001, p. 26).

\section{Considerações finais}

Com os resultados obtidos durante a pesquisa, percebe-se que o Ecoturismo em Alagoas tem um potencial natural para se tornar em ferramenta de boas práticas ambientais através da educação ambiental como incentivadora da preservação dos recursos naturais e a interpretação ambiental como forma de aprendizado e experiência vivenciada nos ambientes naturais. É importante que no planejamento de programas de interpretação ambiental, deva buscar o maior número de informações possíveis, como também a colaboração de técnicos de diferentes áreas: educação, turismo, biologia, história, geografia e arquitetura para desenvolver um amplo diagnóstico ambiental e cultural da área a ser interpretada.

As experiências vivenciadas e as observações abordadas trouxeram uma nova perspectiva sobre a conservação ambiental no Estado de Alagoas. A pesquisa demonstrou que através de boas práticas ambientais com métodos didáticos educacionais como a interpretação ambiental, pode despertar uma conscientização ambientalista das pessoas que visitam a áreas naturais para a conservação desses atrativos.

\section{Referências bibliográficas}

ALAGOAS. Guia de Informações Turísticas. Ano III - № 3, 2003.

ALAGOAS. A reserva da biosfera da Mata Atlântica no estado de Alagoas. Caderno $n^{\circ}$ 29, Conselho Nacional da Reserva da Biosfera da Mata Atlântica, 2004.

ALAGOAS. Plano de manejo da área de proteção do Marituba do Peixe, aprovado em 26 de janeiro de 2006, pelo CEPRAM - conselho estadual de proteção ao meio ambiente. Governo do Estado de Alagoas - Companhia de Desenvolvimento dos Vales do São Francisco e do Parnaíba. Maceió: Secretaria Executiva de Meio Ambiente, Recursos Hídricos e Naturais / Instituto do Meio Ambiente, 2006.

BRASIL. Ministério do Meio Ambiente. Conselho Nacional do Meio Ambiente. CONAMA, 2002.

BRASIL. Instituto Brasileiro de Geografia e Estatística. Disponível em: www.ibge.gov.br, acesso em 21 de maio de 2012.

CEBALLOS-LASCURIÁIN, H.. O ecoturismo como um fenômeno mundial. São Paulo: SENAC,2001, Pág.26.

COMUNIDADES BENTÔNICAS. http://www.icbs.ufal.br/ grupo pesquisa/ comunidadesbentonicas - litoral de Alagoas. Acesso em: 21 de Agosto, 2009. 
DIAS, R. Turismo sustentável e meio ambiente. São Paulo: Atlas, 2003.

DIAS, R. Manual de melhores práticas para o ecoturismo: Interpretação ambiental. Funbio; Ecobrasil, 2004.

EGYDIO, L.M.B. Interpretação ambiental: trilhas autoguiadas no Pantanal. Monografia do curso de pós-graduação em ecoturismo. São Paulo: Senac, 1999.

JESUS, J.S.; RIBEIRO, E.M.S.; FERRAZ, E.M.N. Interpretação ambiental no bioma da caatinga: potencialidades para o ecoturismo no Parque Nacional do Catimbau, Buíque, Pernambuco. Revista Nordestina de Ecoturismo, Aracaju, v.1, n.1, p.61, 2008.

LOPES, J.L. Projeto de implantação do Parque Paleontológico do Município de Maravilha/AL e o turismo científico como alternativa sustentável. Alagoas, 2007.

NATURE UP MAGAZINE. Ecoturismo cresce $20 \%$ ao ano. Disponível em:< http://natureup.com/magazine. Powered by Joomla>. Acesso em: 14 de Agosto, 2009.

OMENA, J.K.M. Proposta para implantação de equipamentos para o turismo de observação de aves na Área de Proteção Ambiental (APA) do Marituba do Peixe. Trabalho de Conclusão do Curso de Bacharelado em Turismo na Faculdade de Alagoas - FAL; Alagoas, 2006.

OVERMUNDO. http://www.overmundo.com.br/quia/parque-municipal-2\#. Acesso em: 14 de Agosto, 2009.

ROCHA, O. Maravilha: Sítio paleontológico vai virar atrativo no sertão. Revista Venha Ver, Maceió, ano VII - oㅜ 34, p.8 e 9, 2007.

SALLES, V. Guia de meio ambiente: litoral de Alagoas. Maceió: Editora AL, $2^{\mathrm{a}}$ Edição Revisada, 1994.

SALLES, V. Guia de meio ambiente: interior de Alagoas. Maceió: Editora AL, 1995.

SWARBROOK, J. Turismo de Aventura. Rio de Janeiro: Elsevier, 2003.

\section{Agradecimentos}

Aos informantes dos locais visitados e colaboração para as fotografias. Aos colegas da turma de Pós-Graduação em Gestão Ambiental da Universidade Estadual de Alagoas - Campus I em Arapiraca-AL. Aos professores orientadores: Rubens Pessoa de Barros, Valdevan Rosendo dos Santos. 
Rubens Pessoa de Barros: Universidade Estadual de Alagoas, Arapiraca, AL, Brasil.

E-mail: pessoa.rubens@gmail.com

Link para o currículo Lattes: http://lattes.cnpq.br/2511101759444154

James Barros dos Santos: Universidade Estadual de Alagoas, Arapiraca, AL, Brasil.

E-mail: jamesecotur@hotmail.com

Link para o currículo Lattes: http://lattes.cnpq.br/5058135866181739

Data de submissão: 27 de maio de 2012

Data de recebimento de correções: 27 de março de 2014

Data do aceite: 27 de março de 2014

Avaliado anonimamente 